Semantic neighbours in facilitated naming

\title{
Investigation of the effects of semantic neighbours in aphasia: a
} facilitated naming study.

Solène Hameau ${ }^{\mathrm{a} *}$, Britta Biedermann ${ }^{\mathrm{b}}$, Nora Fieder ${ }^{\mathrm{c}}$ and Lyndsey Nickels ${ }^{\mathrm{a}}$.

${ }^{a}$ Department of Cognitive Science, Macquarie University, Sydney, Australia;

${ }^{b}$ School of Occupational Therapy, Social Work and Speech Pathology, Curtin University, Perth, Australia; ${ }^{c}$ Berlin School of Mind and Brain, Humboldt-Universität, Berlin, Germany.

\author{
*Corresponding Author: \\ Dr Solène Hameau \\ Department of Cognitive Science \\ Australian Hearing Hub \\ 16, University Avenue \\ MACQUARIE UNIVERSITY, 2109, NSW
}

AUSTRALIA

solene.hameau@students.mq.edu.au

Keywords: aphasia; treatment; facilitated naming; semantic neighbourhood density; association strength.

Word count: 6,879 
BACKGROUND: It is well established that word retrieval can be improved in people with aphasia. However, there has been little research regarding the influence of specific word properties on the success of such treatment.

AIMS: This study aimed to better understand the mechanisms supporting naming treatment effects in aphasia, by exploring effects of word-specific semantic neighbourhood variables (based on featural overlap or on association strength) on the outcomes of a facilitation task. METHODS AND PROCEDURES: Two individuals, one with primarily lexical-semantic difficulties (SJS) and one with primarily lexical difficulties (DEH) participated. Their picture naming performance was assessed before and after a facilitation task in which each target word was repeated in the presence of the corresponding picture.

OUTCOMES AND RESULTS: Both participants showed improved naming following the facilitation task. However, for DEH, inhibitory effects of words with many semantic neighbours were enhanced by the facilitation task. For SJS, in contrast, targets with a strongly associated word in the lexicon were less likely to result in a semantic error compared to those with an associate of weaker association strength.

CONCLUSIONS: It is hypothesised that individuals like DEH, with lexical retrieval impairments, may show increased sensitivity to neighbourhood density, whereas individuals like SJS, with an impairment of the links between semantics to lemmas, may show sensitivity to other neighbourhood measures that are more likely to be encoded at the semantic level.

Abstract word count: 229 words 
Semantic neighbours in facilitated naming

\section{Introduction}

What makes a given word easier or harder to retrieve from memory? Addressing this question is relevant both when one wants to conceptualise word retrieval processes in unimpaired speakers and in individuals with aphasia, and when developing therapies that can benefit word retrieval in people with aphasia.

The production of a spoken word is often viewed as a series of steps where selection between relevant representations is required (e.g., Levelt, Roelofs, \& Meyer, 1999). In particular, it is typically assumed that before selection of the right word form, one has to 'choose' between semantically similar alternatives that are concurrently activated. Research has addressed the question of whether semantically related words compete for selection, using for example picture-word interference (e.g., Glaser \& Glaser, 1989; La Heij, 1988) or semantic blocking (e.g., Kroll \& Stewart, 1994) tasks. However, in situations when there is no manipulation of semantic context, the precise nature and impact of co-activated semantic representations during (unimpaired or aphasic) word production remains unclear (see below). Moreover, the potential interaction of these co-activated representations with the effectiveness of word retrieval treatment in aphasia has, to our knowledge, not yet been investigated.

In fact, there has been relatively little attention to date regarding the impact of specific properties of the words used in aphasia treatment on the effectiveness of that treatment: Are some words in the lexicon more likely to benefit from naming therapy than others? This knowledge has implications both for treatment and for theories of word production. For example, in bilinguals with aphasia: cognate words seem to promote better cross-language generalisation than non-cognates (e.g., Kohnert, 2004, but see Kurland \& Falcon, 2011, for effects in the opposite direction). There are other studies that find that different classes and subclasses of words, show different responses to treatment, for example (object) nouns generate better treatment outcomes than (action) verbs (Conroy, Sage, and Lambon Ralph, 
Semantic neighbours in facilitated naming

2009), suggesting either a different representation for nouns and verbs, or, as Conroy and colleagues do acknowledge, a better sensitivity to treatment for more imageable words (nouns were more imageable than verbs in their set). In contrast, Romanova (2015) found no difference in the sensitivity to facilitation for common versus proper nouns. Finally, and particularly relevant to this study, Kiran and Thompson (2003) argued that, following treatment, only items that were atypical of their semantic category showed generalisation to other words within the category following semantic treatment. Based on Plaut's (1995) model of typicality in reading, the authors suggested that exposure to atypical items, that share some features of the prototype but also disparate features, results in activation of both typical and atypical items, whereas exposure to typical items results in activation only of a limited set of items with shared features.

Consequently, taken together there is there is some evidence that other semantic properties of words may influence the success of treatment. Here we aim to extend this literature by exploring how semantic neighbourhood affects the outcome of a naming facilitation task with people with aphasia. In doing so we hope to inform our understanding of factors influencing treatment effectiveness in aphasia, and also the theoretical debate on word retrieval. Facilitation, in this context, refers to the effect of performing one task on the accuracy of another task examined a short time later (e.g., Howard, Patterson, Franklin, Orchard-Lisle, \& Morton, 1985). It can be compared to a long lag priming technique in healthy speakers. It has been suggested that the results of facilitation may predict the results of treatment (e.g., Hickin, Best, Herbert, Howard, and Osborne, 2002).

\section{Semantic neighbourhood: feature-based versus association-based measures}

Often research distinguishes between two broad types of semantic relationships: taxonomic relationships, represented by coordinates (words that belong to the same 
Semantic neighbours in facilitated naming

taxonomic category and share semantic features; e.g. carrot - turnip) and thematic relationships, represented by words that are associatively related (that do not necessarily share features, e.g., carrot - rabbit). These two types of semantic relationships have been shown to produce different effects in the picture-word interference paradigm (where a picture has to be named in the presence of a superimposed written word distractor, such as naming a picture of a carrot with either 'turnip' or 'rabbit' written on it): Coordinates seem to yield interference (e.g., Alario, Segui, \& Ferrand, 2000; La Heij, Dirkx, \& Kramer, 1990, but see Mahon, Costa, Peterson, Vargas, \& Caramazza, 2007), whereas associates seem to generate facilitation (e.g., Alario, Segui, \& Ferrand, 2000; Costa, Alario, \& Caramazza, 2005; Cutting \& Ferreira, 1999; La Heij, Dirkx, \& Kramer, 1990; Sailor, Brooks, Bruening, Seiger-Gardner, \& Guterman, 2009). Taxonomic knowledge has also been claimed to be represented in a different brain location to thematic knowledge (e.g., Schwartz et al., 2011; see Mirman, Landrigan, \& Britt, 2017 for a review of similar findings).

Much of the research examining effects of semantic neighbourhood on picture naming, in situations when there is no manipulation of semantic context (as is the case in the study we report here), has focused on number of taxonomic semantic neighbours (but see Hameau, Nickels, \& Biedermann, 2017, 2019, who found no effect of any semantic neighbourhood type in an investigation of the effect of different types of neighbourhoods on picture-naming in unimpaired participants). In people with aphasia, there is some evidence that the number of semantic neighbours (i.e., semantic neighbourhood density) has an influence on spoken word production, in standard spoken picture naming tasks (with no manipulation of the presence of semantically related words), but the effects reported on accuracy are inconsistent (No effect: Blanken, Dittmann, \& Wallesch, 2002; Bormann, 2011; Bormann, Kulke, Wallesch, \& Blanken, 2008; Inhibitory effect : Mirman, 2011; Facilitatory effect: Kittredge, Dell, \& Schwartz, 2007; Facilitatory or inhibitory effects depending on the 
Semantic neighbours in facilitated naming

participant: Hameau, 2016; Hameau, Nickels, \& Biedermann, 2017, 2019; Mirman \& Graziano, 2013).

\section{Influence of semantic neighbours on the effects of facilitation}

Given that semantic factors (such as item typicality, Kiran \& Thompson, 2003) have been argued to have influence effectiveness of treatment for word retrieval, it seems plausible that semantic neighbourhood variables may also have an effect. However, predictions with respect to the direction of the influence of semantic neighbourhood variables in speech production depend on the processing assumptions of the theories under consideration. For example, if competition is present between similar representations at the lemma level (as in WEAVER ++: Levelt, Roelofs, and Meyer, 1999), increases in semantic neighbourhood would be expected to result in a larger cohort of activated representations resulting in inhibition of naming. Alternatively, in a model where there is no competition but only different activation levels of related representations and, crucially, interactivity between the semantic and the lexical level (e.g., Dell, 1986; Dell, Schwartz, Martin, Saffran, \& Gagnon, 1997), production of the target would be predicted to be facilitated by its semantic neighbours (i.e., in this case, words that share semantic features with the target).

An interesting account that incorporates both taxonomic and thematic semantic relationships is the Swinging Lexical Network hypothesis (e.g., Abdel Rahman \& Aristei, 2010; Abdel Rahman \& Melinger, 2009a, 2009b; Rabovsky, Schad, \& Abdel Rahman, 2016). This account assumes, like most theoretical accounts, that a cohort of semantically related words is activated at the lexical level. Both the number of activated items in the cohort as well as their level of activation contribute to the degree of competition at this level. Facilitation, on the other hand, is thought to occur when the activation/priming of a semantically related representation does not result in lexical activation of a large set of words, hence causing net facilitation. This is the case, for instance, if a word is primed by an associated word that does 
Semantic neighbours in facilitated naming

not share many features with the target, such a word will not be a strong lexical competitor but will add to the activation of the target.

This account suggests that feature-based and association-based neighbourhood measures may affect picture naming behaviour differently depending on the level of impairment of an individual with aphasia. It could be hypothesised that an individual with an impairment at the lexical level would show more interference from words with many / strongly activated feature-based neighbours, while an individual with difficulties in the conceptual-lexical connections might benefit from words that have strongly associated neighbours (if these words generate stronger activation from the conceptual level).

Predictions of the influence of semantic neighbours on the effects of facilitation on naming also depend on the mechanism by which facilitation is effective: at what level does priming occur and does only the target benefit from priming, or also related representations? There is a relative consensus that facilitation as a result of priming occurs by virtue of a strengthening of the links between the semantic representation and its corresponding phonological form, with many authors suggesting more specifically it is between the semantic representation and the lemma (e.g., Howard, Nickels, Coltheart, \& Cole-Virtue, 2006; Oppenheim, Dell, \& Schwartz, 2010; Vitkovitch \& Humphreys, 1991; but for an alternatives, priming from lemma to phonological form, see e.g., Howard, Hickin, Redmond, Clark, and Best (2006), Wheeldon \& Monsell, 1994).

Taking these possible mechanisms underlying facilitation into account, what role could the semantic neighbours of a word play in modulating the outcomes of facilitation? Whether or not semantic neighbours are primed during the facilitation task also depends on the scope of priming is thought to occur. First, it is possible that, when a target is retrieved, priming only occurs for that target, and co-activated semantic neighbours are not primed. If this is the case, potential effects of semantic neighbours (of any type) might be expected to 
reduce as a result of the facilitation task: the increased activation of the target (as a result of priming) relative to the activation of the (unprimed) neighbours would result in neighbours having less of an effect than previously. Another possibility would be that co-activated semantic neighbours are also primed along with the target during the facilitation phase: when the target lemma is active, connections from the semantic features shared with semantic neighbours to the lemmas of those semantic neighbours will also be active. Consequently, these connection weights could also be altered during the priming event. If the connection weights for neighbours are strengthened then the lemmas of the neighbours would also be more active at later naming, however, whether this results in a change in the effect of semantic neighbours is hard to predict and depends on how much neighbours receive priming relative to the target. There would need to be sufficient supplementary activation of the neighbours to change the balance of activation of these neighbours relative to the target, for increased effects of neighbours to be observed. Alternatively, with priming, the connection weights for neighbours could be weakened in parallel to those of the target being strengthened (Oppenheim et al., 2010), this would result in weaker effects of neighbours on naming following priming.

The combination of the two sources of potential priming (of target and neighbours), and the variety of potential effects of (different measures of) neighbourhood on naming therefore lead to many potential patterns of effects, particularly in combination with different levels of spoken word retrieval impairment. For instance, Best, Herbert, Hickin, Osborne, and Howard (2002), suggest that lasting effects of facilitation are more likely in individuals with an impairment in the mapping from semantics to phonology, as opposed to individuals with a semantic impairment or with an impairment at the phonological output level. This study is a first exploration of these mechanisms and will ask the question: Does the semantic neighbourhood of a word affect the extent to which a facilitation task improves naming? We 
Semantic neighbours in facilitated naming

compare the effects of facilitation in two participants with aphasia with different levels of impairment in word retrieval, and analyse the effects of different measures of semantic neighbourhood based on feature overlap or association. This aims to give some insight into the role of semantic neighbours in naming facilitation and contribute to a better understanding of both the dynamics of speech production and mechanisms of language recovery with facilitation in aphasia.

\section{Methods}

\section{Participants}

Two monolingual English-speaking men with chronic post-stroke aphasia took part in this study: DEH and SJS. Both participants were right-handed, with corrected-to-normal vision and normal hearing. Both had previously been involved in several aphasia-related research projects (e.g., Biedermann, Beyersmann, Mason, \& Nickels, 2013; Fieder, Nickels, Biedermann, \& Best, 2015; Mason et al., 2011). An aphasia-friendly consent form was signed by both participants prior to the study. Participants were selected because previous assessment showed they produced predominantly semantic errors and few phonological errors in naming, consistent with impaired word retrieval.

DEH was 71 years old at the time of the study, 12 years after the onset of aphasia following an infarct in the territory of the left Middle Cerebral Artery that was secondary to infective endocarditis. He worked as a typesetter prior to his stroke but was retired. His language difficulties were predominantly in production, with non-fluent speech and anomia, while his comprehension was largely preserved.

SJS was 53 years old and had suffered a left CVA (left Middle Cerebral Artery territory and frontal lobe) 16 years prior to the study. SJS was working part time in an adapted work setting. Before his stroke, he worked as project manager in a telecommunication 
Semantic neighbours in facilitated naming

company. SJS presented with non-fluent aphasia (communicating mostly with single words), deep dyslexia and comprehension difficulties. In the context of conversation these comprehension difficulties were attenuated.

In order to determine the type and extent of the language impairment for both participants, a number of background assessment tasks were carried out. The results of these tests are summarised in Table 1 and Table 2.

(Tables 1 and 2 about here)

DEH showed good auditory comprehension, indicating intact lexical-semantic processing, but he had difficulties in understanding written language, especially when dealing with syntactically complex sentences or abstract words, suggesting impaired access from the written modality. On the other hand, SJS showed impaired comprehension in both the auditory and written modalities, with better comprehension in the context of paragraphs or sentences.

Both participants' connected speech was non-fluent (see Appendix A for samples of spoken picture description for each participant), and both showed difficulties in spoken and written picture naming (24 item naming test). DEH was numerically less accurate on longer words (this was confirmed by a significant effect of length on accuracy in the experimental picture naming task, see later). His incorrect responses on this test were mostly omissions (67\%), phonological errors (25\%) especially on consonant clusters, in addition to some semantic errors $(8 \%)$. He made no semantic errors in written picture naming. His repetition and reading aloud were impaired for words with consonant clusters, long words, and nonwords. The type of errors produced, length effect, difficulties in repetition together with the absence of a conceptual or semantic processing deficit indicate that $\mathrm{DEH}$, in addition to lexical-syntactic difficulties, most likely had an impairment at the level of the phonological 
Semantic neighbours in facilitated naming

output lexicon and/or the link between the lexical-syntactic (lemma) level and phonological output lexicon, as well as an impairment of the phonological output buffer.

SJS produced predominantly semantic errors and semantic descriptions in naming although he made some phonological errors on longer words. He showed no clear length effect in spoken picture naming, and this was confirmed in analyses of the experimental picture naming task. His error pattern, suggests his impairment is predominantly at the link between conceptual and lexical representations. However, he also performed outside the normal range on several repetition tasks, which indicates an additional mild impairment of the phonological output buffer. In addition, SJS was severely impaired in every task involving written language, in both input and output modalities. We do not detail further the impairments in written language of our participants, given the focus of this study is on spoken word production.

\section{Materials}

197 black and white drawings from the International Picture Naming Project (IPNP: Szekely et al., 2004) were selected. These pictures were chosen because they depicted single words and appeared both in McRae et al.'s feature norm database (McRae, Cree, Seidenberg, \& McNorgan, 2005), and in the Edinburgh Associative Thesaurus (Kiss, Armstrong, Milroy, \& Piper, 1973). The McRae et al. feature norm database (McRae et al., 2005) is a corpus of 541 concepts for which features have been generated by participants who were asked to provide semantic features that best described each concept. The Edinburgh Associative Thesaurus is a set of word association norms (Kiss et al., 1973): each stimulus word in the database was presented to 100 different subjects, who, for each word, had to write down the first word that came to mind, as quickly as possible. Of the 197 items, 196 were included in the final analysis, as the word bag was consistently named paper bag and was therefore removed. For 
Semantic neighbours in facilitated naming

these items, measures pertaining to a number of control variables as well as the critical semantic variables were retrieved (see Appendix B for the detail of these measures). Control predictors included trial number, objective visual complexity, log word form frequency, name agreement, age of acquisition, familiarity, imageability, phonological neighbourhood density and length in phonemes. Semantic neighbourhood variables ${ }^{1}$ included measures based on features (taxonomic relationship) and association (thematic relationship). Feature-based measures (McRae et al., 2005) were: Semantic neighbourhood density (SND), Proportion of shared features between the target and its closest neighbour (CloseSim), and Number of feature-based close neighbours that are higher in frequency than the target word, (HighFreqSND). The measure based on association norms (Kiss et al., 1973) was Association strength (StrengthAsso) $)^{2}$.

\section{Procedure}

The facilitation task used was repetition and/or reading of the target word in the presence of its corresponding picture and written form (RRIPP; e.g., Croot et al., 2015). While Howard et al. (2006a) used word-to-picture matching, similar effects have been found following application of a range of different tasks in treatment and/or facilitation of word retrieval in aphasia (Howard, 2000; Howard et al., 1985; Nickels, 2002). Specifically, tasks that require activation of both semantics (e.g., from presentation of the picture) and word form (e.g., from repeating the word) have all been argued to engage similar mechanisms and hence tasks that focus on 'semantic' processing (e.g., word-to-picture matching) have similar outcomes as those with a 'phonological' focus (e.g., phonemic cueing, repetition in the presence of the picture; Howard, 2000; Nickels, 2002).

The experimental stimuli were randomly allocated to two sets and the facilitated naming procedure was run over two experimental sessions: 
Semantic neighbours in facilitated naming

Session 1

1a. Picture naming of the first 99 items (baseline, set 1),

1b. Facilitation of these 99 items in blocks of around 20 followed by naming of each block of items (facilitated naming and post-test, set 1).

\section{Session 2}

2a. Picture naming of the remaining 98 items (baseline, set 2),

2b. Facilitation of these 98 items in blocks of around 20 followed by timed naming of those 20 items (facilitated naming and post-test, set 2).

The baseline and post-facilitation picture naming followed the same procedure: pictures were presented centred on a laptop screen, using the software DMDX (Forster \& Forster, 2003), and each picture appeared concurrently with a beep. The participant was asked to name the picture with a single word. The picture remained on the screen until the participant gave a response or indicated his failure to respond (there was no time out), and the next picture was presented upon the examiner's button press. The whole naming session was audio recorded using a digital voice recorder. Naming responses and response latency (time between the onset of the beep and start of the participant's response) were transcribed and calculated using Audacity (Mazzoni, Brubeck, \& Haberman, 2005).

Facilitated naming was organised in five blocks of approximately 20 items, as follows: the first 20 pictures were displayed one after another on a laptop screen, along with the written name represented by the picture, while the examiner said the target word aloud. Presentation of the target was hence multimodal, providing many opportunities for facilitation (Best, Howard, Bruce, \& Gatehouse, 2008). The participant was instructed to repeat/read the target word. Each word had to be produced (successfully) by the participant, and, in case of 
Semantic neighbours in facilitated naming

error, the participant was asked to repeat it again until correct production of the target word was achieved, while the picture and corresponding written word were still displayed.

Participants were aware that they would have to name these pictures again, later that session, and were encouraged to try to remember the names (although awareness of the requirement for subsequent naming does not impact effectiveness, see Howard et al., 2006). Performance during the facilitated naming task was not recorded.

After this facilitated naming task, and a short intervening chat with the examiner (about 3-5 minutes), the same 20 pictures were presented again for naming using the same paradigm as during baseline naming. Pictures were presented in a different order in the facilitation task and in the final naming task, but pseudo-randomization in both facilitation and post-naming ensured that the two words that preceded or followed the target were not from the same semantic category. Following this first block, the remaining pictures were presented for facilitated naming and post-test using the same procedure, in four blocks of 19 or 20 items. Participants were free to take longer breaks between each block if they wished.

\section{Response coding}

The first complete response was coded, excluding false starts and subsequent (correct or incorrect) responses. Correct responses consisted of a correctly pronounced target word, with no phonological error. Plural errors (“ants" instead of "ant") were accepted as correct. Acceptable alternatives were plausible alternative labels for the picture (e.g., trousers for pants). Omissions were instances were no response was made, or a comment expressing failure to respond (e.g., "I don't know"). Semantic errors consisted of a single noun, and were clearly semantically related to the target. Semantic errors were further split in four subcategories: superordinate (e.g., toy for ball), subordinate (e.g., polar bear for bear), coordinate (another member of the same semantic category, e.g., skirt for dress), and 
Semantic neighbours in facilitated naming

associate (a noun with no taxonomic relationship with the target, but related in meaning through association, e.g., snow for skis). Formal errors were word responses that shared at least $50 \%$ of their phonemes with the target or vice versa (target shared at least $50 \%$ of its phonemes with the response, e.g., rate for rake). Non-words were phonologically- related responses that were not real words but that shared at least $50 \%$ of their phonemes in common with the target, or vice versa (e.g., 'beaner' for beaver). Mixed errors both shared a semantic relationship with the target and met the criteria for a formal error (e.g., basket for box).

Unrelated word errors were real words sharing no semantic relationship and less that $50 \%$ of phonemes with the target (e.g., giraffe for canoe). Descriptions were an attempt to describe the target (its appearance, use, etc...), and could be a single word, provided this was not a noun (e.g., sweep for broom). Errors that did not fall into any of these categories were labelled as other errors (these errors were exclusively, non-words with less than $50 \%$ of phonemes shared with the target, e.g., "igla" for deer). $20 \%$ of responses were independently coded by two assessors experienced in error response coding, and resulted in 96\% inter-rater agreement; disagreements were resolved by consensus. Consistent with background testing, DEH produced more omission errors than other error types, whereas SJS produced more semantic errors.

\section{Analyses}

Separate analyses were performed for each participant using R (R Core Team, 2014). Analyses targeted naming behaviour (response time, accuracy and semantic errors) for each participant over the whole experiment, but also investigated whether performance was affected differently by the semantic variables at baseline compared to post-test.

For each participant, linear mixed effect models (using the package lme4: Bates, Mächler, Bolker, \& Walker, 2014) were applied to response latency for items that were 
Semantic neighbours in facilitated naming

correct both at baseline and at post-test, and generalised linear mixed effects models for binomial outcomes were applied to each participant's complete set of responses, to analyse the influence of each semantic factor on changes in response accuracy between baseline and post-test, or, for semantic errors, to analyse their influence of the probability of a semantic error compared to a correct response. In these linear mixed effects models, target item was entered with a random intercept, and control predictors described earlier were supplemented with the factor "time" (baseline vs post-test). First, all control fixed predictors were added to the base model, and non-significant predictors were removed in a stepwise fashion if they did not significantly improve the model (using likelihood-ratio tests). Next, the critical semantic predictors were each entered into base models, together with the interaction of that predictor with time. We did not include all experimental predictors (the semantic neighbourhood variables) in the model simultaneously, as some were correlated risking multicollinearity. This was especially true for the feature-based measures: SND and HighFreqSND: $r=.67$, $\mathrm{p}<.001 ;$ SND and CloseSim: $r=.527, \mathrm{p}<.001 ;$ HighFreqSND and CloseSim: $r=.372, \mathrm{p}<.001$ ); StrengthAsso was correlated with SND (r=-.155, p=.03) and CloseSim (r=-.145, p=.042). We applied correction for multiple comparisons (Holm-Bonferroni).

\section{Results}

Overall, performance was better at post-test than at baseline for both participants, likely due to the beneficial effect of the facilitation task (see Table 3).

(Table 3 about here)

\section{DEH: response latency analysis}

DEH named 71 words correctly at both baseline and post-test. Following a Box Cox test (Box \& Cox, 1964), data was inverse transformed (to the power of -1.5), and the one data point that remained more than 2.5 standard deviations away from the mean was removed, 
Semantic neighbours in facilitated naming

along with the other instance when this word was named (two data points were therefore removed, resulting in 140 observations to be analysed).

(Table 4 about here)

The base model (see Table 4) included target item as a random factor, and the significant fixed factors frequency and time: more frequent words were faster named as at baseline, and items that were correct both at baseline and at post-test were named significantly faster after facilitation, showing the overall effectiveness of facilitation on response latency for $\mathrm{DEH}$.

When the critical semantic neighbourhood predictors were each entered into base models, no semantic neighbourhood variable showed an interaction with time. A main marginal effect of HighFreqSND was observed: words tended to be faster named if they had fewer semantic neighbours of higher frequency than the target.

\section{DEH: accuracy analysis}

The base model for DEH's accuracy included time, length in phonemes, and visual complexity as fixed effects. DEH's accuracy was significantly better at post-test than at baseline, showing again the likely beneficial effect of facilitation. In addition, words were more likely to be more accurately named overall if they were visually more complex and with fewer phonemes.

At baseline, correctly and incorrectly named words had a similar average number of higher frequency neighbours (respectively 1.34 and 1.42) but at post-test, correct words had fewer higher frequency neighbours than incorrect words (respectively 1.08 and 1.91), showing a numerical advantage of words with few of these neighbours. However, the effect was not statistically significant, as the interaction between time and number of higher frequency neighbours disappeared after correction for multiple comparisons. 
Semantic neighbours in facilitated naming

\section{DEH: semantic error analysis}

The base model only included time as a fixed effect: words at post-test were more likely to be named accurately than to result in a semantic error than words at baseline, and the other control predictors did not reach significance.

There was a significant interaction between time and both HighFreqSND and SND. More specifically, words that had resulted in a semantic error at baseline that were correctly named after the facilitation task (30 words) were low in SND and HighFreqSND. A small number of words (2) were correctly named at baseline and resulted in a semantic error after facilitation: these words were particularly high in the semantic neighbourhood predictors. Response combinations at baseline and post-test as a function of semantic neighbourhood variables that significantly affected this response comparison are displayed in Table 5.

(Table 5 about here)

\section{SJS: response latency analysis}

SJS named 88 words correctly at both baseline and post-test. Following response latency inverse transformation (to the power of -1.15 , according to the result of a Box Cox test: Box and Cox, 1964), no data point was more than 2.5 standard deviation away from the mean and hence all 176 observations were used in the analyses. The base model included target item as a random factor (with random intercept), and time and frequency as fixed control factors (see Table 6). More frequent words were faster named overall, and time was only marginally significant (words tended to be faster named at post-test than at baseline), showing that the facilitation task had no reliable effect on SJS's response time. None of the semantic neighbourhood measures showed significant effects nor significantly interacted with time for response latency (all p>.4) (see Table 6).

(Table 6 about here) 
Semantic neighbours in facilitated naming

\section{SJS: accuracy analysis}

The base generalised linear mixed effect model included time, frequency and phonological neighbourhood density (see Table 6). There was a significant effect of time, showing the beneficial effect of facilitation on accuracy for SJS (as opposed to its only marginal effect on latencies), and words that were more frequent and had more phonological neighbours were more accurately named overall.

No semantic neighbourhood measure either had a significant main effect or significantly interacted with time in predicting accuracy after correction for multiple comparisons.

\section{SJS: semantic error analysis}

The base model for correct responses compared to semantic errors included time (words were more likely to be accurately named than to result in a semantic error after facilitation compared to baseline), age of acquisition and phonological neighbourhood density (words acquired later and with fewer phonological neighbours were more likely to result in a semantic error than in a correct response than words acquired earlier and with many phonological neighbours).

(Table 7 about here)

While the interaction between time and association strength (StrenghAsso) did not survive correction for multiple comparisons (corrected $\mathrm{p}=.19$ ), the trend was present when using the University of South Florida norms (Nelson, McEvoy, \& Schreiber, 2004) to calculate association strength (see Table 6). This replication using different norms suggests that the effect of association strength is not significant by 'chance'. This interaction shows a beneficial effect of this variable on the effects of the facilitation task (see Table 7 for average StrengthAsso in each response combination from baseline and post-test). Those words that 
Semantic neighbours in facilitated naming

resulted in a semantic error at baseline but that were correctly named after the facilitation task had higher StrengthAsso than the mean, whereas those that also resulted in a semantic error after facilitation had lower StrengthAsso than the mean.

\section{Discussion}

In this study, we used a facilitated naming paradigm with two individuals with aphasia with different patterns of word retrieval impairment, in order to investigate the potential influence of aspects of semantic neighbourhood.

Several measures relating to different facets of the semantic neighbourhood of words were used: measures based on the featural overlap between the target and semantically related words (including measures pertaining to the number of neighbours, to their similarity with the target, or to their frequency), or based on associative relationships between the target and words in the lexicon (strength of the association of the closest associate).

(Table 8 about here)

A summary of the findings is shown in Table 8. DEH and SJS appeared to be differently affected by neighbourhood measures, particularly in the extent to which these effects were influenced by the facilitation task. DEH's performance was affected by neighbourhood density measures (SND, number of semantic neighbours, and HighFreqSND, number of neighbours of higher frequency than the target), whereas SJS was affected by the strength of association between the target and its first associate (StrengthAsso).

For $\mathrm{DEH}$, the number of feature-based neighbours of higher frequency than the target (marginally) influenced response latency for correctly named words: naming was somewhat slower for words with many of these neighbours. DEH had unimpaired semantic processing, but impaired lexical (lemma and phonological form) retrieval and phonological buffer impairment. An inhibitory effect of neighbours on response time is generally hypothesised to 
Semantic neighbours in facilitated naming

be caused by the activation of neighbours at the lemma level slowing selection, either because of increased lateral inhibition, or because increased total activation of non-target lemmas slows selection under the Luce choice rule (e.g., Levelt et al., 1999; Roelofs, 1992).

Intuitively, then, this inhibition should be stronger when neighbours are higher in frequency than the target, as the activation levels for these neighbours would be relatively greater than for words of lower frequency ${ }^{3}$. Since DEH's impairment lies mostly at post-semantic levels, activation at the semantic level (e.g., of semantic features) should be adequate, but at the lemma level, impaired processing could lead to an increased influence of co-activated words that are high in frequency, resulting in the observed effect increased latencies for words with many (higher frequency) semantic neighbours. This pattern of inhibition on latency is incompatible with most theories that do not have competition (e.g., Dell, 1986; Dell et al., 1997; Morton, 1980).

DEH benefitted substantially from the facilitation task, with faster latencies on correct words, better accuracy and fewer semantic errors after this task. With respect to the semantic neighbourhood variables, it seems that the items that benefitted the most from facilitation (i.e., resulted in fewer semantic errors) were those items with few feature-based semantic neighbours (low SND), and especially those with few neighbours of higher frequency than the target. In comparison, those words with many such neighbours did not improve to the same extent. In other words, there was an increase in the size of the inhibitory effect of semantic neighbours following facilitation. This finding fits best with the most commonly accepted view that priming occurs as a result of the strengthening of links between semantics and lemmas (e.g., Howard, Nickels, et al., 2006; Oppenheim et al., 2010; Vitkovitch \& Humphreys, 1991), and suggests that links for semantic neighbours are also strengthened following the facilitation task. This could generate stronger (inhibitory) effects of these semantic neighbours whose lemmas "compete" with the target lemma. One would have to 
Semantic neighbours in facilitated naming

assume that the balance of activation between the target lemma and the neighbours changes as a function of the facilitation task, with semantic neighbours comparatively more active relative to the target after facilitation than before.

SJS showed no effect of any semantic variables on naming before facilitation. However, he also benefitted from the facilitation task, with better accuracy and fewer semantic errors, as well as marginally faster reaction times on correct responses. But the pattern of interaction between semantic neighbourhood variables and the effects of facilitation was different from that of DEH. Indeed, for SJS, words that benefitted the most (in terms of reducing semantic errors), were those with a strongly associated first associate. It has been postulated that associates might be encoded at the lexical level and be activated by virtue of lateral activation (e.g., Weigl \& Bierwisch, 1970, cited in Nickels, 1997). If this flow of activation was hypothesised to be bidirectional (from target to associate and then back to target), potential effects of associated words could be explained, but it is unclear how these effects would be facilitatory. Alternatively, Collins \& Loftus (1975) postulate that different types of semantic relationships are encoded at the conceptual level. These include associative relationships (e.g., street-vehicle). In their account, semantic representations are not comprised of features but rather non-decomposed conceptual nodes. These nodes have stronger links between them depending on how often the linked concepts are used together. Hence, in this account, an influence of (strongly) associated words could occur at the conceptual level, and the effect could be facilitatory because of stronger activation of the target concept via these links (see also Abdel Rahman \& Melinger, 2009a, 2009b).

SJS likely has an impairment at the links between the semantic and the lemma levels. It is therefore likely that SJS's naming may be better for words that generate stronger activation at the semantic level. A possible mechanism that could be responsible for this effect following the facilitation task, would be that those words that have a stronger semantic 
Semantic neighbours in facilitated naming

activation (by virtue of strong associative links) benefit more from the strengthening of connection weights between semantics and lemmas (as in Howard, Nickels, et al., 2006) as they have stronger input to these links.

It is important to note that this study is preliminary, but it provides a first step in the investigation the role that semantic neighbourhood measures may have in anomia treatment. The effects we find are not strong, and consequently replication in different participants with similar levels of impairment to DEH and SJS is required, in order to assess the generalisability of the role of these semantic variables in aphasia treatment, as well as the relevance in the context of word production and priming theories.

\section{Conclusions}

This study used a facilitated naming paradigm with two individuals with aphasia in order to investigate how semantic neighbours in the lexicon interact with (long-lag) priming. Semantic neighbourhood is a complex notion and the influence of having many similar words in the lexicon on the ease of naming is still not well understood. The results of this study once again show this complexity. Nevertheless, this study has shed more light on which semantic neighbourhood variables affect word retrieval in aphasia and whether, as well as how, different types of impairment lead to different sensitivities to some of these measures. We found that an increased number of feature-based neighbours, especially if these are highly activated (i.e., high frequency), led to poorer performance (longer response times) in DEH, an individual who had an impairment at the lexical/lemma level. This is in line with some theories of (unimpaired) spoken word production that postulate that semantically similar representations compete for selection at the lemma level (e.g., Levelt et al., 1999; Roelofs, 1992). We found, in SJS, an individual with a likely impairment of the links between semantic and lemma representations, that following a priming task, words with a strong 
Semantic neighbours in facilitated naming

associate resulted in fewer errors. Hence we hypothesised that associative relationships may be coded at the conceptual level, resulting in increased target activation that reduces the likelihood of a semantic error in individuals with an impairment of the links from semantics, especially when the target word has been primed.

Taken together, the different effects of the number of semantic neighbours in DEH, and association strength in SJS, are compatible with the Swinging Lexical Network hypothesis (e.g., Abdel Rahman \& Melinger, 2009b): conceptual facilitation for SJS coming from strongly associated words, and lexical inhibition for DEH coming from words with many (highly) activated semantic neighbours, either arising following the facilitation task, or being enhanced by it. Both replication of these results and computational modelling are required in order to fully understand the complex interactions of factors in lexical access, especially with language impairment.

In terms of how priming occurs in anomia treatment, these findings are consistent with the dominant view that priming consists of strengthening the mapping between semantics and the lemma level (e.g., Howard et al., 2006; Oppenheim et al., 2010; Vitkovitch \& Humphreys, 1991), and suggests that semantically related representations might also be primed in the process.

With respect to implications for treatment of word retrieval, and pending replication, these results lead us to tentatively suggest that individuals with an impairment between the semantic and lemma level may improve more on those words that have strong associates, but for individuals with lexical impairments, the presence of highly activated semantic neighbours might interfere with the ease of lexical access and limit treatment effects, and it might therefore be better to focus on words that have few semantic neighbours. 
Semantic neighbours in facilitated naming

\section{Foot / endnotes}

${ }^{1}$ In a previous version of this study which formed part of the first author's $\mathrm{PhD}$ thesis (Hameau, 2016), we also examined seven additional semantic neighbourhood measures. We did not include these analyses here as these measures were all moderately or highly correlated to at least one of the four measures reported here. These measures were: Mean similarity of neighbours (the average of the proportion of shared features between the target and all its neighbours); Number of higher frequency neighbours, based on lemma frequency; Word-form frequency of the closest semantic neighbour; Lemma frequency of the closest semantic neighbour; Number of associates; Word-form and Lemma frequency of the first associate.

${ }^{2}$ We replicated the analyses performed with these association-based measures using another database (The University of South Florida Word Association, Rhyme and Word Fragment Norms: Nelson, McEvoy, \& Schreiber, 2004; we had originally chosen the Edinburgh database as being perhaps more culturally similar to our Australian population). Four items from our set were missing from these norms (ostrich, peacock, pineapple, skis). Association strength for the 192 overlapping items ranged from 9-88, average=31.61, $\mathrm{SD}=15.98$ ). As for the Edinburgh database, on average, about $18 \%$ of the first associates were also coordinates of the target. Although the two measures were only moderately correlated $(\mathrm{r}=.55, \mathrm{p}<.001)$, significant effects of StrengthAsso were maintained (or even stronger) in these additional analyses using the Nelson et al. (2004) database (see Table 6).

\footnotetext{
${ }^{3}$ While some theories state that frequency affects phonological retrieval but not lemma retrieval (e.g., Levelt et al., 1999) it has also been hypothesised that frequency effects arise
} 
Semantic neighbours in facilitated naming

both at the level of phonological retrieval and at the level of lemma retrieval (see Kittredge,

Dell, Verkuilen, \& Schwartz, 2008, for a review). 
Semantic neighbours in facilitated naming

\section{Acknowledgements}

We thank DEH and SJS for their participation to this study. We thank David Howard and Wendy Best for helfpul discussions when the experiment was being planned. We thank Serje Robidoux for very useful statistics advice. An earlier version of this paper was written as part of the first author's Ph.D thesis, funded by an International Macquarie University Research Excellence Scholarship (iMQRES). During the preparation of this paper Solène Hameau was funded by the Australian Research Council Centre of Excellence in Cognition and its Disorders (CCD) [CE110001021]. Lyndsey Nickels was funded by an Australian Research Council Future Fellowship [FT120100102].

\section{Disclosure of interest}

The authors report no conflict of interest. 
Semantic neighbours in facilitated naming

\section{References}

Abdel Rahman, R., \& Aristei, S. (2010). Now you see it . . and now again: Semantic interference reflects lexical competition in speech production with and without articulation. Psychonomic Bulletin and Review, 17(5), 657-661. https://doi.org/10.3758/PBR.17.5.657

Abdel Rahman, R., \& Melinger, A. (2007). When Bees Hamper the Production of Honey: Lexical Interference From Associates in Speech Production. Journal of Experimental Psychology: Learning Memory and Cognition, 33(3), 604-614. https://doi.org/10.1037/0278-7393.33.3.604

Abdel Rahman, R., \& Melinger, A. (2009a). Dismissing lexical competition does not make speaking any easier: A rejoinder to Mahon and Caramazza (2009). Language and Cognitive Processes, 24(5), 749-760. https://doi.org/10.1080/01690960802648491

Abdel Rahman, R., \& Melinger, A. (2009b). Semantic context effects in language production: A swinging lexical network proposal and a review. Language and Cognitive Processes, 24(5), 713-734. https://doi.org/10.1080/01690960802597250

Alario, F. -Xavier, Ferrand, L., Laganaro, M., New, B., Frauenfelder, U. H., \& Segui, J. (2004). Predictors of picture naming speed. Behavior Research Methods, Instruments, \& Computers, 36(1), 140-155. https://doi.org/10.3758/BF03195559

Alario, François-Xavier, Segui, J., \& Ferrand, L. (2000). Semantic and associative priming in picture naming. The Quarterly Journal of Experimental Psychology, 53A(3), 741-764.

Baayen, H. R., \& Milin, P. (2010). Analyzing Reaction Times. International Journal of Psychological Research, 3(2), 12-28. Retrieved from http://www.redalyc.org/html/2990/299023506003/

Bates, D., Mächler, M., Bolker, B., \& Walker, S. (2014). Fitting Linear Mixed-Effects Models using lme4. Journal of Statistical Software. Retrieved from http://arxiv.org/abs/1406.5823

Best, W., Herbert, R., Hickin, J., Osborne, F., \& Howard, D. (2002). Phonological and orthographic facilitation of word-retrieval in aphasia: Immediate and delayed effects. Aphasiology, 16(1-2), 151-168. https://doi.org/10.1080/02687040143000483

Best, W., Howard, D., Bruce, C., \& Gatehouse, C. (2008). A Treatment for Anomia Combining Semantics, Phonology and Orthography. In Language Disorders in Children 
Semantic neighbours in facilitated naming

and Adults: Psycholinguistic Approaches to Therapy (pp. 102-129). https://doi.org/10.1002/9780470699157.ch7

Biedermann, B., Beyersmann, E., Mason, C., \& Nickels, L. (2013). Does plural dominance play a role in spoken picture naming? A comparison of unimpaired and impaired speakers. Journal of Neurolinguistics, 26(6), 712-736.

https://doi.org/10.1016/J.JNEUROLING.2013.05.001

Blanken, G., Dittmann, J., \& Wallesch, C.-W. (2002). Parallel or serial activation of word forms in speech production? Neurolinguistic evidence from an aphasic patient. Neuroscience Letters, 325(1), 72-74. https://doi.org/10.1016/S0304-3940(02)00227-6

Bormann, T. (2011). The Role of Lexical-Semantic Neighborhood in Object Naming: Implications for Models of Lexical Access. Frontiers in Psychology, 2, 127. https://doi.org/10.3389/fpsyg.2011.00127

Bormann, T., Kulke, F., Wallesch, C.-W., \& Blanken, G. (2008). Omissions and semantic errors in aphasic naming: Is there a link? Brain and Language, 104(1), 24-32. https://doi.org/10.1016/J.BANDL.2007.02.004

Box, G. E. P., \& Cox, D. R. (1964). An Analysis of Transformations. Journal of the Royal Statistical Society. Series B (Methodological), Vol. 26, pp. 211-252. https://doi.org/10.2307/2984418

Collins, A. M., \& Loftus, E. F. (1975). A Spreading-Activation Theory of Semantic Processing. Psychological Review, 82(6), 407-428. Retrieved from https://pdfs.semanticscholar.org/6137/4d14a581b03af7e4fe0342a722ea94911490.pdf

Conroy, P., Sage, K., \& Lambon Ralph, M. A. (2009). Errorless and errorful therapy for verb and noun naming in aphasia. Aphasiology, 23(11), 1311-1337. Retrieved from http://search.ebscohost.com/login.aspx?direct=true \&AuthType=ip,shib\&db=jlh\&AN=10 $5329232 \&$ site $=$ ehost-live $\&$ scope $=$ site

Costa, A., Alario, F. X., \& Caramazza, A. (2005). On the categorical nature of the semantic interference effect in the picture-word interference paradigm. Psychonomic Bulletin and Review, 12(1), 125-131. https://doi.org/10.3758/BF03196357

Croot, K., Taylor, C., Abel, S., Jones, K., Krein, L., Hameister, I., ... Nickels, L. (2015). Measuring gains in connected speech following treatment for word retrieval: A study with two participants with primary progressive aphasia. Aphasiology, 29(11), 1265- 
Semantic neighbours in facilitated naming

1288. https://doi.org/http://dx.doi.org/10.1080/02687038.2014.975181

Cutting, J. C., \& Ferreira, V. S. (1999). Semantic and Phonological Information Flow in the Production Lexicon. Journal of Experimental Psychology : Learning, Memory and Cognition, 25(2), 318-344.

Davis, C. J. (2005). N-Watch: A program for deriving neighborhood size and other psycholinguistic statistics. Behavior Research Methods, 37(1), 65-70. https://doi.org/10.3758/BF03206399

Dell, G. S. (1986). A spreading activation theory of retrieval in language production. Psychological Review, 93, 283-321.

Dell, Gary S., Schwartz, M. F., Martin, N., Saffran, E. M., \& Gagnon, D. A. (1997). Lexical Access in Aphasic and Nonaphasic Speakers. Psychological Review, 104(4), 801-838. https://doi.org/10.1037/0033-295X.104.4.801

Fieder, N., Nickels, L., Biedermann, B., \& Best, W. (2015). How 'some garlic' becomes 'a garlic' or 'some onion': Mass and count processing in aphasia. Neuropsychologia, 75, 626-645. https://doi.org/10.1016/J.NEUROPSYCHOLOGIA.2015.06.031

Fieder, N., Wartenburger, I., \& Abdel Rahman, R. (2018). A close call: Interference from semantic neighbourhood density and similarity in language production. Memory \& Cognition, 1-24. https://doi.org/10.3758/s13421-018-0856-y

Forster, K. I., \& Forster, J. C. (2003). DMDX: A Windows display program with millisecond accuracy. Behavior Research Methods, Instruments, \& Computers, 35(1), 116-124. https://doi.org/10.3758/BF03195503

Glaser, W. R., \& Glaser, M. O. (1989). Context effects in Stroop-like word and picture processing. Journal of Experimental Psychology: General, 118(1), 13-42. https://doi.org/10.1037/0096-3445.118.1.13

Grainger, J., O’Regan, J. K., Jacobs, A. M., \& Segui, J. (1989). On the role of competing word units in visual word recognition: The neighborhood frequency effect. Perception \& Psychophysics, 45(3), 189-195. https://doi.org/10.3758/BF03210696

Grainger, J., \& Segui, J. (1990). Neighborhood frequency effects in visual word recognition: A comparison of lexical decision and masked identification latencies. Perception \& Psychophysics, 47(2), 191-198. https://doi.org/10.3758/BF03205983 
Semantic neighbours in facilitated naming

Hameau, S. (2016). Neighbourhood density effects in spoken word production. Macquarie University, Sydney, Australia.

Hameau, S., Nickels, L. A., \& Biedermann, B. (2017). Influential neighbours? The role of semantic neighbours in word production. Academy of Aphasia 55th Meeting. Retrieved from

https://www.frontiersin.org/10.3389/conf.fnhum.2017.223.00117/event_abstract?sname= Academy_of_Aphasia_55th_Annual_Meeting_

Hameau, S., Nickels, L., \& Biedermann, B. (2019). Effects of Semantic Neighbourhood Density on Spoken Word Production. Quarterly Journal of Experimental Psychology, 174702181985985. https://doi.org/10.1177/1747021819859850

Hickin, J., Best, W., Herbert, R., Howard, D., \& Osborne, F. (2002). Phonological therapy for word-finding difficulties: A re-evaluation . Aphasiology, pp. 16(10-11): 981-999. Retrieved from http://www.informaworld.com/smpp/title content=t713393920

Howard, D, Hickin, J., Redmond, T., Clark, P., \& Best, W. (2006). Re-Visiting “Semantic Facilitation" of Word Retrieval for People with Aphasia: Facilitation Yes But Semantic No. Cortex, 42(6): 946-962.

Howard, David. (2000). Cognitive neuropsychology and aphasia therapy: the case of word retrieval. In I. Papathanasiou (Ed.), Acquired neurogenic communication disorders: A clinical perspective. Retrieved from https://www.researchgate.net/publication/258046196_Cognitive_neuropsychology_and_ aphasia_therapy_the_case_of_word_retrieval

Howard, David, Nickels, L., Coltheart, M., \& Cole-Virtue, J. (2006). Cumulative semantic inhibition in picture naming: experimental and computational studies. Cognition, 100(3), 464-482. https://doi.org/10.1016/J.COGNITION.2005.02.006

Howard, David, Patterson, K., Franklin, S., Orchard-lisle, V., \& Morton, J. (1985). The facilitation of picture naming in aphasia. In Cognitive Neuropsychology (Vol. 2). https://doi.org/10.1080/02643298508252861

Kay, J., Lesser, R., \& Coltheart, M. (1996). Psycholinguistic assessments of language processing in aphasia (PALPA): An introduction. Aphasiology, 10(2), 159-180. https://doi.org/10.1080/02687039608248403

Kiran, S., \& Thompson, C. K. (2003). The role of semantic complexity in treatment of 
Semantic neighbours in facilitated naming

naming deficits: training semantic categories in fluent aphasia by controlling exemplar typicality. Journal of Speech, Language \& Hearing Research, 46(4), 773-787. Retrieved from

http://search.ebscohost.com/login.aspx?direct=true \&AuthType=ip,shib\&db=jlh\&AN=10 $6702343 \&$ site $=$ ehost-live $\&$ scope $=$ site

Kiss, G., Armstrong, C., Milroy, R., \& Piper, J. (1973). An associative thesaurus of English and its computer analysis. In A. J. Aitkin, R. W. Bailey, \& N. Hamilton-Smith (Eds.), The computer and literary studies. Retrieved from https://www.bibsonomy.org/bibtex/2a5a7debef9c7b1747209b47ae80687e8/josephauster wei

Kittredge, A. K., Dell, G. S., \& Schwartz, M. F. (2007). Omissions in aphasic picture naming: Late age-of-acquisition is the culprit, not low semantic density. Brain and Language, 103(1-2), 132-133. https://doi.org/10.1016/j.bandl.2007.07.081

Kittredge, A. K., Dell, G. S., Verkuilen, J., \& Schwartz, M. F. (2008). Where is the effect of frequency in word production? Insights from aphasic picture-naming errors. Cognitive Neuropsychology, 25(4), 463-492. https://doi.org/10.1080/02643290701674851

Kohnert, K. (2004). Cognitive and cognate-based treatments for bilingual aphasia: A case study. Brain and Language, 91(3), 294-302. https://doi.org/http://dx.doi.org/10.1016/j.bandl.2004.04.001

Kroll, J. F., \& Stewart, E. (1994). Category Interference in Translation and Picture Naming: Evidence for Asymmetric Connections Between Bilingual Memory Representations. Journal of Memory and Language, 33(2), 149-174. https://doi.org/10.1006/JMLA.1994.1008

Kurland, J., \& Falcon, M. (2011). Effects of cognate status and language of therapy during intensive semantic naming treatment in a case of severe nonfluent bilingual aphasia. Clinical Linguistics \& Phonetics, 25(6-7), 584-600. https://doi.org/10.3109/02699206.2011.565398

La Heij, W. (1988). Components of Stroop-like interference in picture naming. Memory \& Cognition, 16(5), 400-410. https://doi.org/10.3758/BF03214220

La Heij, W., Dirkx, J., \& Kramer, P. (1990). Categorical Interference and Associative Priming in Picture Naming. British Journal of Psychology, 81, 511-525. 
Semantic neighbours in facilitated naming

Levelt, W. J. M., Roelofs, A., \& Meyer, A. S. (1999). A theory of lexical access in speech production. Behavioral and Brain Sciences, 22(1999), 1-37.

Mahon, B. Z., Costa, A., Peterson, R., Vargas, K. A., \& Caramazza, A. (2007). Lexical Selection Is Not by Competition: A Reinterpretation of Semantic Interference and Facilitation Effects in the Picture-Word Interference Paradigm. Journal of Experimental Psychology: Learning Memory and Cognition, 33(3), 503-535. https://doi.org/10.1037/0278-7393.33.3.503

Mason, C., Nickels, L., McDonald, B., Moses, M., Makin, K., \& Taylor, C. (2011). Treatment of word retrieval impairments in aphasia: Evaluation of a self-administered home programme using personally chosen words . Aphasiology, pp. 25(2): 245-268. Retrieved from http://www.informaworld.com/smpp/title content=t713393920

Mazzoni, D., Brubeck, M., \& Haberman, J. (2005). Audacity: Free audio editor and recorder. Retrieved from http://audacity.sourceforge.net

McRae, K., Cree, G. S., Seidenberg, M. S., \& McNorgan, C. (2005). Semantic feature production norms for a large set of living and nonliving things. Behavior Research Methods, 37(4), 547-559. https://doi.org/10.3758/BF03192726

Mirman, D. (2011). Effects of near and distant semantic neighbors on word production. Cognitive, Affective, \& Behavioral Neuroscience, 11(1), 32-43. https://doi.org/10.3758/s13415-010-0009-7

Mirman, D., \& Graziano, K. M. (2013). The Neural Basis of Inhibitory Effects of Semantic and Phonological Neighbors in Spoken Word Production. Journal of Cognitive Neuroscience, 25(9), 1504-1516. https://doi.org/10.1162/jocn_a_00408

Mirman, D., Landrigan, J.-F., \& Britt, A. E. (2017). Taxonomic and thematic semantic systems. Psychological Bulletin, 143(5), 499-520. https://doi.org/http://dx.doi.org/10.1037/bul0000092

Morton, J. (1980). The logogen model and orthographic structure. Cognitive Processes in Spelling, 117-133.

Nelson, D. L., McEvoy, C. L., \& Schreiber, T. A. (2004). The University of South Florida free association, rhyme, and word fragment norms. Behavior Research Methods, Instruments, \& Computers, 36(3), 402-407. https://doi.org/10.3758/BF03195588

Nickels, L. (1997). Spoken word production and its breakdown in aphasia. Retrieved from 
Semantic neighbours in facilitated naming

https://www.routledge.com/Spoken-Word-Production-and-Its-Breakdown-InAphasia/Nickels/p/book/9780863774669

Nickels, L. (2002). Therapy for naming disorders: Revisiting, revising, and reviewing. Aphasiology, 16(10-11), 935-979. https://doi.org/http://dx.doi.org/10.1080/02687030244000563

Nickels, L., \& Cole-Virtue, J. (2004). Reading tasks from PALPA: How do controls perform on visual lexical decision, homophony, rhyme, and synonym judgements? Aphasiology, 18(2), 103-126. https://doi.org/10.1080/02687030344000517-633

Nickels, L., \& Howard, D. (1994). A frequent occurrence? factors affecting the production of semantic errors in aphasic naming. Cognitive Neuropsychology, 11(3), 289-320. https://doi.org/10.1080/02643299408251977

Oppenheim, G. M., Dell, G. S., \& Schwartz, M. F. (2010). The dark side of incremental learning: A model of cumulative semantic interference during lexical access in speech production. Cognition, 114(2), 227-252. https://doi.org/10.1016/j.cognition.2009.09.007

Plaut, D. C. (1995a). Connectionist modeling of the breakdown and recovery of reading via meaning. In J. Reggia, R. Berndt, \& E. Ruppin (Eds.), Neural modeling of cognitive and brain disorders (pp. 157-176). New York: Word Scientific.

Plaut, D. C. (1995b). Semantic and Associative Priming in a Distributed Attractor Network. The Seventeenth Annual Conference of the Cognitive Science Society, 37-42. Pittsburgh, Pennsylvania: Lawrence Erlbaum Associates.

R Core Team. (2014). R: A language and environment for statistical computing. Retrieved from http://www.r-project.org/.

Rabovsky, M., Schad, D. J., \& Abdel Rahman, R. (2016). Language production is facilitated by semantic richness but inhibited by semantic density: Evidence from picture naming. Cognition, 146, 240-244. https://doi.org/10.1016/j.cognition.2015.09.016

Richard Ferraro, F., \& Hansen, C. L. (2002). Orthographic neighborhood size, number of word meanings, and number of higher frequency neighbors. Brain and Language, 82(2), 200-205. https://doi.org/10.1016/S0093-934X(02)00016-0

Roelofs, A. (1992). A spreading-activation theory of lemma retrieval in speaking. Cognition, 42(1-3), 107-142. https://doi.org/10.1016/0010-0277(92)90041-F 
Semantic neighbours in facilitated naming

Romanova, A. (2015). Word class effects on representation and processing in non-braindamaged speakers and people with aphasia (Macquarie University, Sydney, Australia). Retrieved from http://minerva.mq.edu.au:8080/vital/access/manager/Repository/mq:44500/SOURCE1

Rose, S. B., Aristei, S., Melinger, A., \& Abdel Rahman, R. (2019). The Closer They Are, the More They Interfere: Semantic Similarity of Word Distractors Increases Competition in Language Production Language processing View project Exploring the neural and cognitive basis of religious thought View project. Journal of Experimental Psychology: Learning, Memory, and Cognition, 45(4), 753-763. https://doi.org/10.1037/xlm0000592

Sailor, K., Brooks, P. J., Bruening, P. R., Seiger-Gardner, L., \& Guterman, M. (2009). Exploring the time course of semantic interference and associative priming in the picture-word interference task. Quarterly Journal of Experimental Psychology, 62(4), 789-801. https://doi.org/10.1080/17470210802254383

Schwartz, M. F., Kimberg, D. Y., Walker, G. M., Brecher, A., Faseyitan, O. K., Dell, G. S., ... Performed, H. B. C. (2011). Neuroanatomical dissociation for taxonomic and thematic knowledge in the human brain. 108(20). https://doi.org/10.1073/pnas.1014935108

Swinburn, K., Porter, G., \& Howard, D. (2004). CAT : comprehensive aphasia test. Retrieved from https://www.routledge.com/Comprehensive-Aphasia-Test/Swinburn-PorterHoward/p/book/9781841693798

Székely, A., Jacobsen, T., D’Amico, S., Devescovi, A., Andonova, E., Herron, D., ... Bates, E. (2004). A new on-line resource for psycholinguistic studies. Journal of Memory and Language, 51(2), 247-250. https://doi.org/10.1016/j.jml.2004.03.002

Vieth, H. E., McMahon, K. L., \& de Zubicaray, G. I. (2014). Feature overlap slows lexical selection: Evidence from the picture-word interference paradigm. Quarterly Journal of Experimental Psychology, 67(12), 2325-2339.

https://doi.org/10.1080/17470218.2014.923922

Vitkovitch, M., \& Humphreys, G. W. (1991). Perseverant responding in speeded naming of pictures: It's in the links. Journal of Experimental Psychology: Learning, Memory, and Cognition, 17(4), 664-680. https://doi.org/10.1037/0278-7393.17.4.664

Weigl, E., \& Bierwisch, M. (1970). Neuropsychology and Linguistics: Topics of Common 
Semantic neighbours in facilitated naming

Research. Foundations of Language, 6(1), 1-18. https://doi.org/10.2307/25000424

Wheeldon, L. R., \& Monsell, S. (1994). Inhibition of Spoken Word Production by Priming a Semantic Competitor. Journal of Memory and Language, 33(3), 332-356.

https://doi.org/10.1006/JMLA.1994.1016 
Semantic neighbours in facilitated naming

\section{Appendix A}

Samples of speech production: picture description from the CAT (Porter and Howard, 2004).

The picture is set in a living room, a man is asleep in an armchair with his feet on a coffee table, and behind him are bookshelves. A cat is sitting on the top shelf trying to get fish from the fishbowl on the shelf below. It has dislodged some books that are about to fall on the man's head. A young child/baby who is playing on the floor is pointing at the cat to warn the man.

DEH:

"The...the cat is...[gesture]... and the books is...[gesture]...boom boom and the...[gesture] sleeping. Uhm...the uh baby is...screaming. Uhm coffee [points at the picture] and the ...uhm...he...yeah and the uh...uhm...the uh...no... [gesture] plants and the uh...T...no the uh [gesture]...yeah...no..."

SJS:

"Sleep...tea... and gone...books...table...up there...em...birds and kitty cat, and and ... 'eheh!'. Flowers...nice, em...baby, girl, man, car uh...radio, and up there [sound of falling], and books...chair...school, books, up there and books [gesture] up there, work, guy [gesture]...yeah, book, up there...[gesture].” 
Semantic neighbours in facilitated naming

\section{Appendix B}

Item-related properties.

In this section we describe the different variables that were used as predictors in response latency and response type analyses. Several variables have been shown to influence latencies in unimpaired picture naming (e.g., Alario et al., 2004; Baayen \& Milin, 2010) and accuracy in picture naming in people with aphasia (e.g., Nickels \& Howard, 1994).

Control predictors. In order to be able to identify an effect of our variables of interest (the semantic neighbourhood variables) over and above the effect of other common predictors of picture naming performance, included as many as possible of these variables as "control predictors".

Trial number: There is evidence of temporal dependencies between successive trials in many experiments for an individual, or 'autocorrelation' (e.g., Baayen \& Milin, 2010): participants may get faster because of task practice, or slower because of fatigue. Including the trial number (position within the experiment) as a predictor allows a better control of these interdependencies.

Objective Visual Complexity: (IPNP, Székely et al., 2004) was the size of the digitized stimuli picture files in Kilobytes, range 4325-62243, average $=16061, S D=8038$.

Log word form frequency: (CELEX: Baayen, Piepenbrock, \& Rijn, 1993): range 0.95-4, average $=2.37, \mathrm{SD}=0.54$

Name agreement: range $0.38-1$, average $0.9, \mathrm{SD}=0.13$. Name agreement values were taken from our own Australian English name agreement data when available $(n=89)$ and were otherwise drawn from the IPNP (Székely et al., 2004).

Age of Acquisition: (Johnston, Dent, Humphreys, \& Barry, 2010): range 1.37-4.97, average $=2.85, \mathrm{SD}=0.73$. 
Semantic neighbours in facilitated naming

Familiarity: (Johnston et al., 2010): range: 2.61-6.84, average=5.09, $\mathrm{SD}=1.10$.

Imageability: (Medical Research Council database: Coltheart, 1981): range 506-668, average $=601.3, \mathrm{SD}=29.4$. Values were only available for 168 of the 196 final items.

Phonological neighbourhood density: (N-Watch: Davis, 2005): range 0-34, average=11, $S D=9.18$.

Length in phonemes: range 2-9, average $=4.28, \mathrm{SD}=1.39$.

Semantic neighbourhood predictors. The semantic neighbourhood variables included in our analyses were based either on feature or on association norms. Feature-based neighbourhood measures were obtained based on McRae and colleagues' (2005) database. Frequency of the semantic neighbours was drawn from CELEX (Baayen et al., 1993). We evaluated the effects of both measures of the number of semantically similar words (density), and also of how similar the most similar neighbours of a target were (e.g., Fieder et al., 2018; Rose, Aristei, Melinger, \& Abdel Rahman, 2019; Vieth, McMahon, \& de Zubicaray, 2014). In addition, we took into account the frequency of these very similar neighbours by using the number of semantic neighbours of higher frequency than the target as another predictor. This is in an analogy to the frequency effects of orthographic neighbours of the target in the visual word recognition literature (e.g., Grainger, O’Regan, Jacobs, \& Segui, 1989; Grainger \& Segui, 1990; Ferraro \& Hansen, 2002).

Semantic neighbourhood density (SND): This was defined as the number of feature-based close neighbours (following Mirman's (2011) definition, words sharing 40\% or more of their semantic features with the target): range 0-36, average $=5.00, S D=6.10$.

Proportion of shared features between the target and its closest neighbour(CloseSim): This measure indicates how "similar" the closest neighbour in the lexicon is: range $0.00-0.93$, average $=0.47, S D=0.27$. 
Semantic neighbours in facilitated naming

Number of feature-based close neighbours that are higher in frequency than the target word, (HighFreqSND): range 0-12, average $=1.38, S D=2.32$.

Association strength was defined using the Edinburgh Association Thesaurus database (Kiss et al., 1973). Association is argued to reflect a different type of semantic relationship to feature-based neighbours, and associates, as mentioned earlier, may be processed differently to coordinates/words that share features with the target (e.g., Abdel Rahman \& Melinger, 2007; Costa, Alario, \& Caramazza, 2005; Plaut, 1995b).

Association strength (StrengthAsso): Percentage of participants choosing the first associate: range 7-65, average $=23.93, \mathrm{SD}=13.41$. This measure represents the strength of the association between the target word and its most frequently given associate. 
Table 1. Background assessment for DEH and SJS: performance on published tests.

\begin{tabular}{|c|c|c|c|}
\hline Task & No. of items & $\%$ Cut-off ${ }^{1}$ & DEH \% \\
\hline
\end{tabular}

\begin{tabular}{lcccc}
\hline Conceptual semantic processing & & & & \\
PPT 3 pictures & 52 & 94 & 100 & 96 \\
$\mathrm{CAT}^{3}$ semantic recognition & 10 & 80 & 90 & 100 \\
CAT semantic memory & 10 & 80 & 90 & 100
\end{tabular}

\section{Comprehension}

Spoken comprehension

CAT spoken word comprehension

15

PALPA $^{4}$ auditory synonym judgement

High imageability

Low imageability

\section{Written comprehension}

CAT written word comprehension

PALPA written synonym judgement

High imageability

Low imageability

Sentence comprehension

CAT spoken sentence comprehension

CAT written sentence comprehension

CAT spoken paragraph comprehension

\section{Production}

\section{Spoken picture naming}

CAT object naming

CAT action naming

5

16

16

4

60

30

30

30

30

83

93

$77 *$

6

0

30

15

90

100

100

0

87

87

$58 *$

91

97

$67 *$

82

$77 *$

$50 *$

Word fluency 


\section{Semantic neighbours in facilitated naming}

CAT word fluency (number of words)

$\mathrm{n} / \mathrm{a}$

13

8*

$7^{*}$

\section{Reading}

CAT word reading

CAT complex word reading

3

67

$0 *$

$0 *$

CAT function word reading

3

50

$33^{*}$

0*

CAT nonword reading

5

60

$0 *$

0*

\section{Repetition}

CAT word repetition

16

91

100

$62 *$

CAT complex word repetition

3

83

$33^{*}$

$0 *$

CAT sentence repetition

12

83

$67 *$

$42 *$

CAT nonword repetition

5

50

$40 *$

$40 *$

PALPA nonword repetition

30

57

73

\section{Writing}

CAT spoken picture description

$\mathrm{n} / \mathrm{a}$

33

$9 *$

$1 *$

${ }^{1}$ Cut-off $=$ score two standard deviations below healthy controls mean. Normal range (when available) $=$ taken from the instruction manuals of respective tests/from the Nickels \& Cole-Virtue (2004) norms. Scores with an asterisk $=$ impaired performance.

${ }^{2}$ PPT: Pyramids and Palms Trees test (Howard \& Patterson, 1992). Percentage at cut-off $=$ lowest boundary of normal range.

${ }^{3}$ CAT: Comprehensive Aphasia Test (Swinburn, Porter, \& Howard, 2004). Cut-off values (percentages) $=$ lowest boundary to be considered unimpaired performance.

${ }^{4}$ PALPA: Psycholinguistic Assessments of Language Processing in Aphasia (Kay, Lesser, \& Coltheart, 1996).

$\mathrm{n} / \mathrm{a}=$ not appropriate 
Semantic neighbours in facilitated naming

Table 2. Background assessment for DEH and SJS: scores on a 24 item naming test

DEH number correct

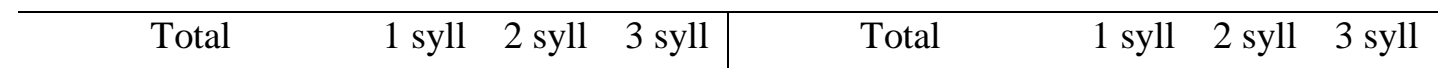

Task

\begin{tabular}{|c|c|c|c|c|c|c|c|c|}
\hline & 124 & 18 & 18 & 18 & 124 & 18 & 18 & 18 \\
\hline Spoken picture naming & 12 & 5 & 5 & 2 & 14 & 4 & 3 & 3 \\
\hline Written picture naming & 12 & 7 & 4 & 0 & 1 & 1 & 0 & 0 \\
\hline Reading & 20 & 7 & 7 & 9 & 15 & 5 & 6 & 4 \\
\hline Repetition & 19 & 7 & 7 & 5 & 23 & 8 & 8 & 7 \\
\hline Writing to dictation & 16 & 8 & 5 & 2 & 2 & 1 & 1 & 0 \\
\hline
\end{tabular}

Legend:

A set of 24 pictured items (taken from the IPNP: Szekely et al., 2004) consisting of 8 words of each of 1, 2, and 3 syllables matched for name agreement, age of acquisition, word form frequency and visual complexity, with the same items assessed across five different modalities (spoken and written picture naming, repetition, reading aloud, and writing to dictation). Accuracy presented for both the whole set (Total) and for the subsets of each syllable length. All items differed from the experimental items for the current study, and assessment in each modality was made on a different day. Norms are not available, but since the same items are used in different tasks, the relative impairment can be compared across modalities. 
Semantic neighbours in facilitated naming

Table 3. Distribution of response types (percentage of the total number of items between brackets) at baseline (BL) and post-test (PT) for both participants, with per item mean and standard deviation of response time (RT) (number of targets: 196).

\begin{tabular}{|c|c|c|c|c|}
\hline & \multicolumn{2}{|c|}{ DEH } & \multicolumn{2}{|c|}{ SJS } \\
\hline & $\mathrm{BL}$ & $\mathrm{PT}$ & $\mathrm{BL}$ & $\mathrm{PT}$ \\
\hline Mean RT (seconds) & 2.54 & 1.64 & 2.09 & 2.62 \\
\hline (SD) & -1.96 & -0.77 & -1.99 & -3.18 \\
\hline Correct & $92(47 \%)$ & $125(64 \%)$ & $99(51 \%)$ & $140(71 \%)$ \\
\hline acceptable alternatives & $6(3 \%)$ & $2(1 \%)$ & $2(1 \%)$ & $3(2 \%)$ \\
\hline omissions & $56(29 \%)$ & $26(13 \%)$ & $14(7 \%)$ & $8(5 \%)$ \\
\hline semantic & $23(12 \%)$ & $7(4 \%)$ & $55(28 \%)$ & $26(13 \%)$ \\
\hline superordinate & 1 & 0 & 1 & 1 \\
\hline subordinate & 1 & 1 & 1 & 1 \\
\hline coordinate & 14 & 4 & 34 & 19 \\
\hline associate & 7 & 2 & 18 & 5 \\
\hline mixed & $1(1 \%)$ & $2(1 \%)$ & $1(1 \%)$ & $3(2 \%)$ \\
\hline formal & $7(4 \%)$ & $7(4 \%)$ & $2(1 \%)$ & $4(2 \%)$ \\
\hline related nonword & $7(4 \%)$ & $14(7 \%)$ & $6(3 \%)$ & $5(3 \%)$ \\
\hline unrelated & 0 & 0 & $2(1 \%)$ & 0 \\
\hline description & $2(1 \%)$ & 0 & $14(7 \%)$ & $4(2 \%)$ \\
\hline other errors & $2(1 \%)$ & $13(7 \%)$ & $2(1 \%)$ & $2(2 \%)$ \\
\hline
\end{tabular}


Table 4. DEH: Summary of the base (generalized) linear mixed effects model on latencies, accuracy, and semantic errors at pre-and post-test, and interactions in each model involving a critical predictor: Variance and Standard Deviation $(S D)$ for the random effect, coefficient estimates $(\beta)$, standard errors $(S E), t$ - or $z$ and $p$-values with corrected $p$-values (Holm-Bonferroni : for the $8 p$-values corresponding to semantic factors in each model) for the fixed effects in the base model and for the interactions in their respective models, and AIC for each model.

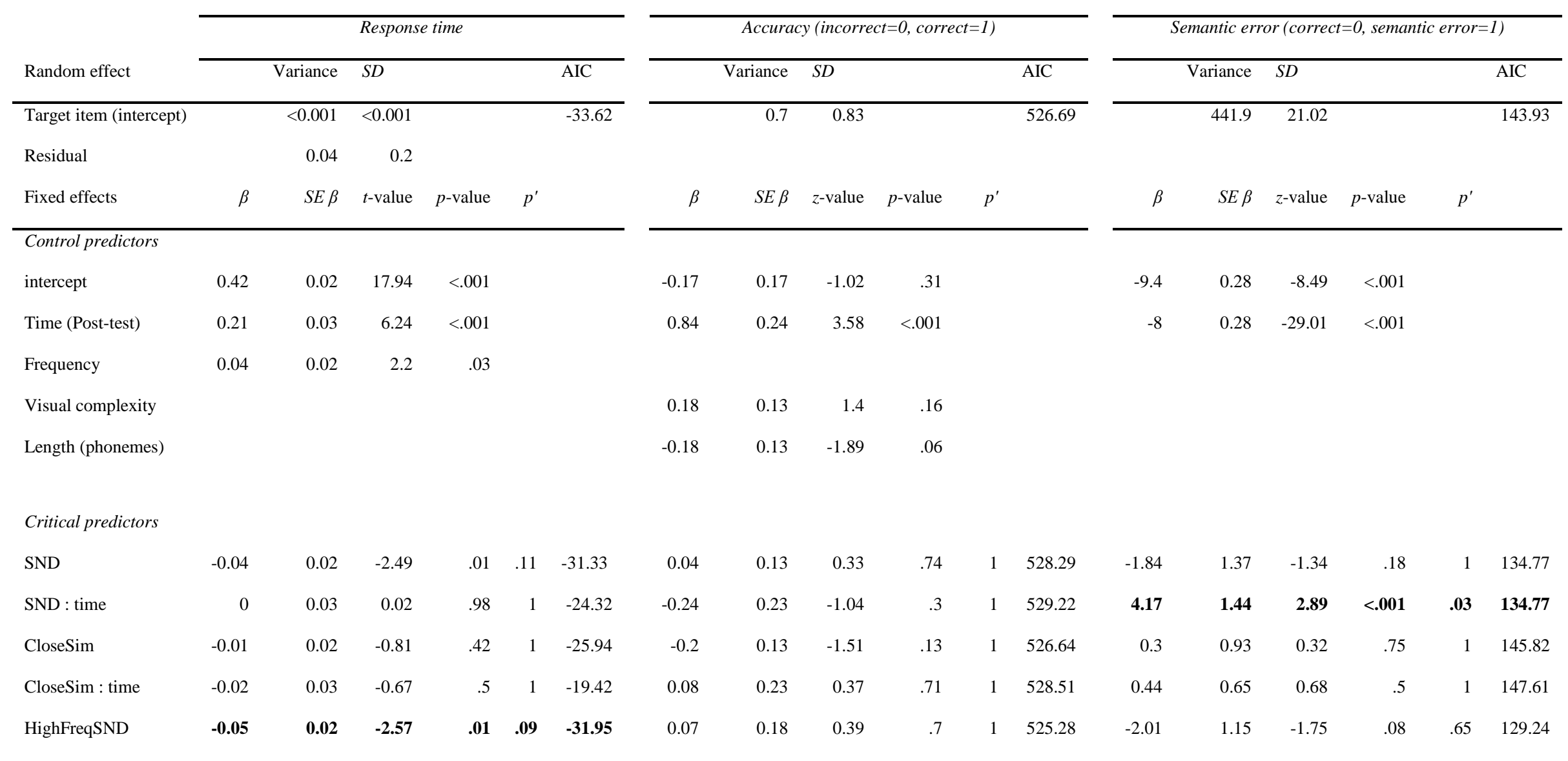


Semantic neighbours in facilitated naming

$\begin{array}{lrrrrrrrrrrrrrrrrrrrrrr}\text { HighFreqSND : time } & 0.03 & 0.03 & 1.03 & .31 & 1 & -25.98 & -0.47 & 0.23 & -2.01 & .04 & 0.36 & 525.28 & \mathbf{4 . 5 9} & \mathbf{1 . 1 2} & \mathbf{4 . 0 9} & <.001 & <.001 & \mathbf{1 2 9 . 2 4} \\ \text { StrengthAsso } & 0 & 0 & 0.04 & .97 & 1 & -20.05 & -0.11 & 0.13 & -0.83 & .41 & 1 & 527.26 & -0.35 & 0.97 & -0.37 & .72 & 1 & 147.77 \\ \text { StrengthAsso : time } & 0 & 0 & -0.57 & .57 & 1 & -8.19 & -0.41 & 0.23 & -1.79 & .07 & 0.59 & 527.26 & 0.12 & 1.07 & 0.11 & .91 & 1 & 147.77\end{array}$

$\mathrm{SND}=$ Semantic Neighbourhood Density, CloseSim=featural overlap with the closest neighbour, HighFreqSND=number of semantic neighbours of higher

frequency than the target, StrengthAsso=strength of the association with the first associate. Significant main effects and interactions between semantic factors and time, are in bold. 
Semantic neighbours in facilitated naming

Table 5. DEH: Mean semantic neighbourhood values for words in different response patterns and their standard deviations for correct responses and semantic errors versus correct responses.

$$
\text { HighFreqSND SND }
$$

Number of words $\quad$ Mean(SD) Mean(SD)

\begin{tabular}{lccc}
\hline whole set & 196 & $1.38(2.32)$ & $5(6.11)$ \\
correct $->$ correct & 69 & $1.16(2.38)$ & $5.20(6.68)$ \\
correct $->$ semantic & 2 & $6(5)$ & $14.5(8.5)$ \\
semantic $>$ > semantic & 3 & $0(0)$ & $3(2.45)$ \\
semantic-> correct & 30 & $0.37(0.70)$ & $2.94(3.91)$
\end{tabular}

correct $=$ correct responses, semantic=semantic errors (includes mixed errors)

SND=Semantic Neighbourhood Density, CloseSim=featural overlap with the closest neighbour, HighFreqSND=number of semantic neighbours of higher frequency than the target 
Semantic neighbours in facilitated naming

Table 6. SJS: Summary of the base (generalized) linear mixed effects model on latencies, accuracy and semantic errors at pre-and post-test, and interactions in each model involving a critical predictor: Variance and Standard Deviation $(S D)$ for the random effect, coefficient estimates $(\beta)$, standard errors $(S E)$, $t$ - or $z$ - and $p$-values with corrected $p$-values (Holm-Bonferroni : for the $8 p$-values corresponding to semantic factors in each model) for the fixed effects in the base model, and for the interactions in their respective models, and AIC for each model.

\begin{tabular}{lccc} 
& \multicolumn{3}{c}{ Response time } \\
\cline { 2 - 4 } & Variance & $S D$ & AIC \\
\hline Random effect & 0.07 & 0.26 & 201.23 \\
\hline Target item (intercept) & 0.11 & 0.33 & \\
Residual & & &
\end{tabular}
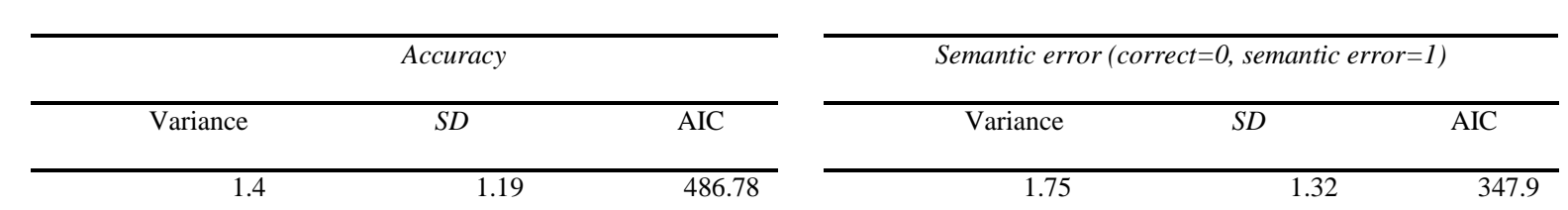

Fixed effects

$$
\beta \quad S E \beta \quad t \text {-value } \quad p \text {-value } \quad p^{\prime}
$$

$\beta$

SE $\beta$

$z$-value $\quad p$-value $p^{\prime}$

\section{Base model}

\section{intercept}

Time (Post-test)

0.05

$18.39<.001$

Frequency

$\begin{array}{llll}0.09 & 0.05 & 1.71 & .09\end{array}$

PND

$\begin{array}{llll}0.09 & 0.04 & 2.35 & .02\end{array}$

Age of Acquisition

Critical predictors

\begin{tabular}{lcccccc}
\hline SND & 0.01 & 0.04 & 0.21 & .83 & 1 & 207.89 \\
SND : time & 0.01 & 0.05 & 0.12 & .91 & 1 & 214.02 \\
CloseSim & -0.03 & 0.04 & -0.82 & .41 & 1 & 207.29
\end{tabular}

\begin{tabular}{cccccc}
0.04 & 0.19 & 0.2 & .85 & & \\
1.2 & 0.28 & 4.33 & $<.001$ & & \\
0.38 & 0.18 & 2.16 & .03 & & \\
0.41 & 0.18 & 2.34 & .02 & & \\
& & & & & \\
& & & & & \\
& & & & & \\
\hline-0.18 & 0.15 & -1.2 & .23 & 1 & 487.33 \\
0.16 & 0.25 & 0.64 & .52 & 1 & 488.92 \\
-0.3 & 0.16 & -1.87 & .06 & .49 & 485.12
\end{tabular}

\begin{tabular}{|c|c|c|c|c|c|}
\hline$\beta$ & $S E \beta$ & $z$-value & $p$-value & $p^{\prime}$ & \\
\hline-0.77 & 0.26 & -3.02 & $<.001$ & & \\
\hline-1.36 & 0.4 & -3.77 & $<.001$ & & \\
\hline-0.43 & 0.2 & -2.16 & .03 & & \\
\hline 0.41 & 0.2 & 2.11 & .04 & & \\
\hline 0.33 & 0.18 & 1.79 & .07 & .59 & 346.44 \\
\hline-0.03 & 0.29 & -0.12 & .9 & 1 & 348.42 \\
\hline-0.36 & 0.2 & -1.82 & .07 & .55 & 344.25 \\
\hline
\end{tabular}


Semantic neighbours in facilitated naming

\begin{tabular}{|c|c|c|c|c|c|c|c|c|c|c|c|c|c|c|c|c|c|c|}
\hline CloseSim : time & -0.04 & 0.05 & -0.78 & .44 & 1 & 212.84 & -0.05 & 0.26 & -0.18 & .86 & 1 & 487.08 & 0.55 & 0.39 & 1.41 & .16 & 1 & 344.07 \\
\hline HighFreqSND & -0.03 & 0.04 & -0.84 & .4 & 1 & 207.1 & -0.18 & 0.17 & -1.03 & .3 & 1 & 487.72 & 0.27 & 0.19 & 1.4 & .16 & 1 & 347.85 \\
\hline SNDh : time & -0.01 & 0.05 & -0.12 & .91 & 1 & 213.24 & 0.27 & 0.26 & 1.05 & .3 & 1 & 488.58 & -0.22 & 0.31 & -0.71 & .48 & 1 & 349.33 \\
\hline StrengthAsso & 0 & 0.04 & -0.07 & .94 & 1 & 207.94 & -0.06 & 0.15 & -0.37 & .71 & 1 & 488.65 & 0.38 & 0.25 & 1.53 & .13 & 1 & 345.68 \\
\hline StrengthAsso : time & 0 & 0.05 & 0.08 & .94 & 1 & 214.09 & 0.42 & 0.26 & 1.61 & .11 & .86 & 487.93 & -0.87 & 0.39 & -2.27 & .02 & .19 & 345.68 \\
\hline \multicolumn{19}{|c|}{ Additional model with StrengthAssoSF } \\
\hline StrengthAssoSF & 0.04 & 0.04 & 1.15 & .25 & 1 & 204.95 & -0.21 & 0.20 & -1.05 & .29 & 1 & 474.74 & 0.29 & 0.24 & 1.222 & .22 & 1 & 333.81 \\
\hline StrengthAssoSF : time & -0.07 & 0.05 & -1.35 & .18 & 1 & 209.30 & 0.68 & 0.29 & 2.34 & .02 & .16 & 474.74 & -1.12 & 0.431 & -2.59 & .01 & .08 & 333.81 \\
\hline
\end{tabular}

SND=Semantic Neighbourhood Density, CloseSim=featural overlap with the closest neighbour, HighFreqSND=number of semantic neighbours of higher frequency than the target, StrengthAsso=strength of the association with the first associate. StrengthAssoSF: StrengthAsso, but based on the South Florida Norms. Significant main effects and interactions between semantic factors and time, are in bold. 
Semantic neighbours in facilitated naming

Table 7. SJS: Mean Strength of Association values for words in different response patterns (with standard deviations), in semantic errors versus correct responses outcomes.

\begin{tabular}{lcc} 
& & StrengthAsso \\
& number of words & Mean (SD) \\
\hline whole set & 196 & $23.93(13.41)$ \\
correct $->$ correct & 85 & $22.6(12.86)$ \\
correct $->$ semantic & 5 & $19.25(10.26)$ \\
semantic $->$ semantic & 14 & $15.6(6.69)$ \\
semantic-> correct & 32 & $28.62(16.03)$ \\
\hline correct $=$ correct responses, semantic=semantic errors (includes mixed errors). \\
StrengthAsso=strength of the association with the first associate.
\end{tabular}


Semantic neighbours in facilitated naming

Table 8. Summary of the findings: effects of semantic neighbourhood factors overall and change following facilitation for DEH and SJS.

\begin{tabular}{|c|c|c|c|c|}
\hline & $\begin{array}{l}\text { Outcome } \\
\text { measure }\end{array}$ & $\begin{array}{l}\text { Significant } \\
\text { effect of } \\
\text { facilitation? }\end{array}$ & $\begin{array}{l}\text { Main effect(s) } \\
\text { overall }\end{array}$ & $\begin{array}{l}\text { Factors influencing } \\
\text { effects of facilitation } \\
\text { (interaction with time) }\end{array}$ \\
\hline \multirow{3}{*}{$\frac{T}{\stackrel{T}{\Delta}}$} & $\begin{array}{l}\text { Response } \\
\text { latency }\end{array}$ & Yes & $\begin{array}{l}\text { Marginally } \\
\text { inhibitory: } \\
\text { HighFreqSND }\end{array}$ & $\varnothing$ \\
\hline & $\begin{array}{l}\text { Correct } \\
\text { responses vs } \\
\text { all errors }\end{array}$ & Yes & $\varnothing$ & $\varnothing$ \\
\hline & $\begin{array}{l}\text { Correct } \\
\text { responses vs } \\
\text { Semantic } \\
\text { errors }\end{array}$ & Yes (fewer) & $\varnothing$ & $\begin{array}{l}\text { Inhibitory: } \\
\text { HighFreqSND \& SND }\end{array}$ \\
\hline \multirow{3}{*}{$\stackrel{\mathscr{\Omega}}{\mathscr{S}}$} & $\begin{array}{l}\text { Response } \\
\text { latency }\end{array}$ & Marginal & $\varnothing$ & $\varnothing$ \\
\hline & $\begin{array}{l}\text { Correct } \\
\text { responses vs } \\
\text { all errors }\end{array}$ & Yes & $\varnothing$ & $\varnothing$ \\
\hline & $\begin{array}{l}\text { Correct } \\
\text { responses vs }\end{array}$ & Yes (fewer) & $\varnothing$ & $\begin{array}{l}\text { Marginally } \\
\text { facilitatory: } \\
\text { StrengthAsso }\end{array}$ \\
\hline
\end{tabular}


Semantic neighbours in facilitated naming

\begin{tabular}{|l|l|l|} 
Semantic & & \\
errors & & \\
\hline
\end{tabular}

